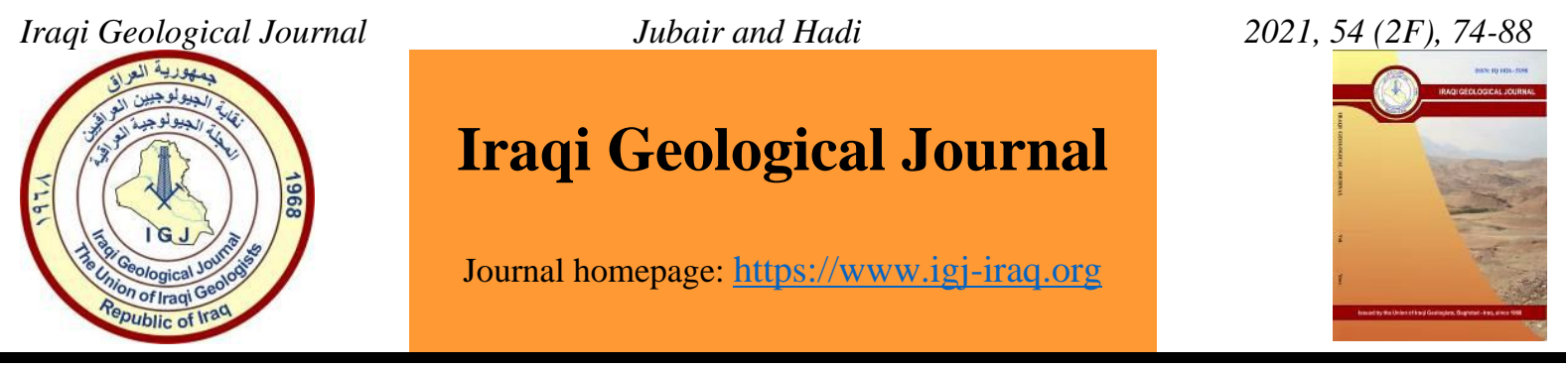

\title{
Development of 1D-Synthetic Geomechanical Well Logs for Applications Related to Reservoir Geomechanics in Buzurgan Oil Field
}

\author{
Qahtan A. Jubair ${ }^{1, *}$ and Farqad A. Hadi ${ }^{1}$ \\ 1 Department of Petroleum Engineering, College of Engineering, University of Baghdad, Baghdad, Iraq \\ * Correspondence: q.jabeer1908m@ coeng.uobaghdad.edu.iq
}

Received: 9 August 2021; Accepted: 21 October 2021; Published: 31 December 2021

\begin{abstract}
Knowledge of the distribution of the rock mechanical properties along the depth of the wells is an important task for many applications related to reservoir geomechanics. Such these applications are wellbore stability analysis, hydraulic fracturing, reservoir compaction and subsidence, sand production, and fault reactivation. A major challenge with determining the rock mechanical properties is that they are not directly measured at the wellbore. They can be only sampled at well location using rock testing. Furthermore, the core analysis provides discrete data measurements for specific depth as well as it is often available only for a few wells in a field of interest. This study presents a methodology to generate synthetic-geomechanical well logs for the production section of the Buzurgan oil field, located in the south of Iraq, using an artificial neural network. An issue with the area of study is that shear wave velocities and pore pressure measurements in some wells are missing or incomplete possibly for cost and time-saving purposes. The unavailability of these data can potentially create inaccuracies in reservoir characterization $\mathrm{n}$ and production management. To overcome these challenges, this study presents two developed models for estimating the shear wave velocity and pore pressure using ANN techniques. The input parameters are conventional well logs including compressional wave, bulk density, and gamma-ray. Also, this study presents a construction of 1-D mechanical earth model for the production section of Buzurgan oil field which can be used for optimizing the selected mud weights with less wellbore problems (less nonproductive time. The results showed that artificial neural network is a powerful tool in determining the shear wave velocity and formation pore pressure using conventional well logs. The constructed 1D MEM revealed a high matching between the predicted wellbore instabilities and the actual wellbore failures that were observed by the caliper $\log$. The majority of borehole enlargements can be attributed to the formation shear failures due to an inadequate selection of mud weights while drilling. Hence, this study presents optimum mud weights ( 1.3 to $1.35 \mathrm{~g} / \mathrm{cc})$ that can be used to drill new wells in the Buzurgan oil field with less expected drilling problems.
\end{abstract}

Keywords: Rock mechanical properties; Artificial neural networks; Reservoir geomechanics

\section{Introduction}

Petroleum geomechanics is the discipline that integrates geophysical, petrophysical, and geological data with rock mechanics to quantify the response of the reservoir to different scenarios of rock failure during drilling operations and well production life (Al-Malikee \& Al-Najim, 2018). Wellbore stability analysis, well design, sand production, and hydraulic fracturing techniques are some applications related to reservoir geomechanics (Hadi et al., 2019). For example, many drilling problems have been addressed

DOI: $\underline{10.46717 / i g j .54 .2 F .7 m s-2021-12-24 ~}$ 
by establishing a 1D mechanical earth modeling (1D-MEM), and thus minimizing drilling problems or reducing the nonproductive time (NPT) (Abdul Aziz \& Abdul Hussein, 2021).

The mechanical properties of borehole-based rock are not directly measured at the wellbore and thereby it is important to relate these properties with other conventional well logs. Such these properties are Young's modulus, Poisson's ratio, shear modulus, and bulk modulus (Elkatatny et al., 2016; Eskandari et al., 2004). Compressional and shear wave velocities are key parameters to obtain the rock mechanical properties (Hadi \& Nygaard, 2018). However, the shear wave velocity data are sometimes missing or incomplete because of the high cost and time taken to acquire the data (Abdul Majeed \& Alhaleem, 2020). Other geomechanical parameters, including overburden stress, minimum and maximum horizontal stresses, pore pressure and rock strength, are also key parameters to construct a geomechanical model for the field of interest (Akhundi et al., 2014). Formation pore pressure (Pp) is an important rock property, which can be used to determine the effective in-situ stresses, thus sufficient mud weights can be selected to drill the well with less expected wellbore instability problems (Zhang, 2011). Many correlations and models have been developed to forecast shear wave velocities and formation pore pressures based on various parameters (Bingham, 1965; Jorden \& Shirley, 1966; Rehm \& McClendon, 1971; Zamora \& Lord, 1974; Eaton, 1975). These models have their own limitations, for example, some of them can only be used in clean shales, or they are only applicable to the pressure generated by the under-compaction mechanism (Ahmed et al., 2019). Furthermore, some of them are not applicable in unloading formations, based on empirical relations and constants that can differ from basins to others. As a result, the accuracy of the reservoir characterization will be decreased which will potentially affect the drilling operations and recovery factors of oil reservoirs. To overcome this challenge in missing data, artificial neural network techniques (ANNs) have been recently applied in petroleum industry to correlate the missing data or key parameters with conventional well logs so that the developed models can be used for further estimation of rock mechanical properties. Hence, the objective of this study is to develop ANN-models to generate shear wave velocity and pore pressure for wells that have missed these properties. Based on that, rock mechanical properties have been established and calibrated with core data to construct a 1-D mechanical earth model for optimum mud weights selection in Buzurqan oil field.

\section{Geological Setting}

\subsection{Area of Study}

Buzurgan oilfield is located in the Missan province in southeastern part of Iraq and near the Iranian border.It is about $175 \mathrm{~km}$ north of Basra and $350 \mathrm{~km}$ southeastern of Baghdad (Fig. 1). Buzurgan oilfield is about $40 \times 7 \mathrm{~km}$, Mishrif Formation is the main producing reservoir in this field (Aldarraji and Almayahi, 2019). Mishrif reservoir in the Buzurgan oilfield appears structurally as a long-axis anticline in the NW-SE direction, with two high-point traps in the south and north connected by a saddle. The northern high-point trap has an area of $3.6 \mathrm{Km}^{2}$, the southern one is larger at $120 \mathrm{Km}^{2}$ (Fig. 2). (AlIsmaily, 2017).

\subsection{Stratigraphy}

The stratigraphic column of the Buzurgan oil field is consisted of two sequences: Cretaceous and Tertiary (Fig. 3). The Tertiary time can be represented by the formations from younger to older: Upper Fars (Injana), Lower Fars (Fatha), Asmari, Jaddala, Aliji, Shiranish, and Hartha, While, Cretaceous are represented by the following formations: Saadi, Tanuma, Khasib, Mishrif, Rumaila, Ahmadi, Maudud, Nahr Umr, and Shuaiba. The lithological description and the geological age for each formation can be described as Fig. 3 (Aldarraji and Almayahi, 2019). 


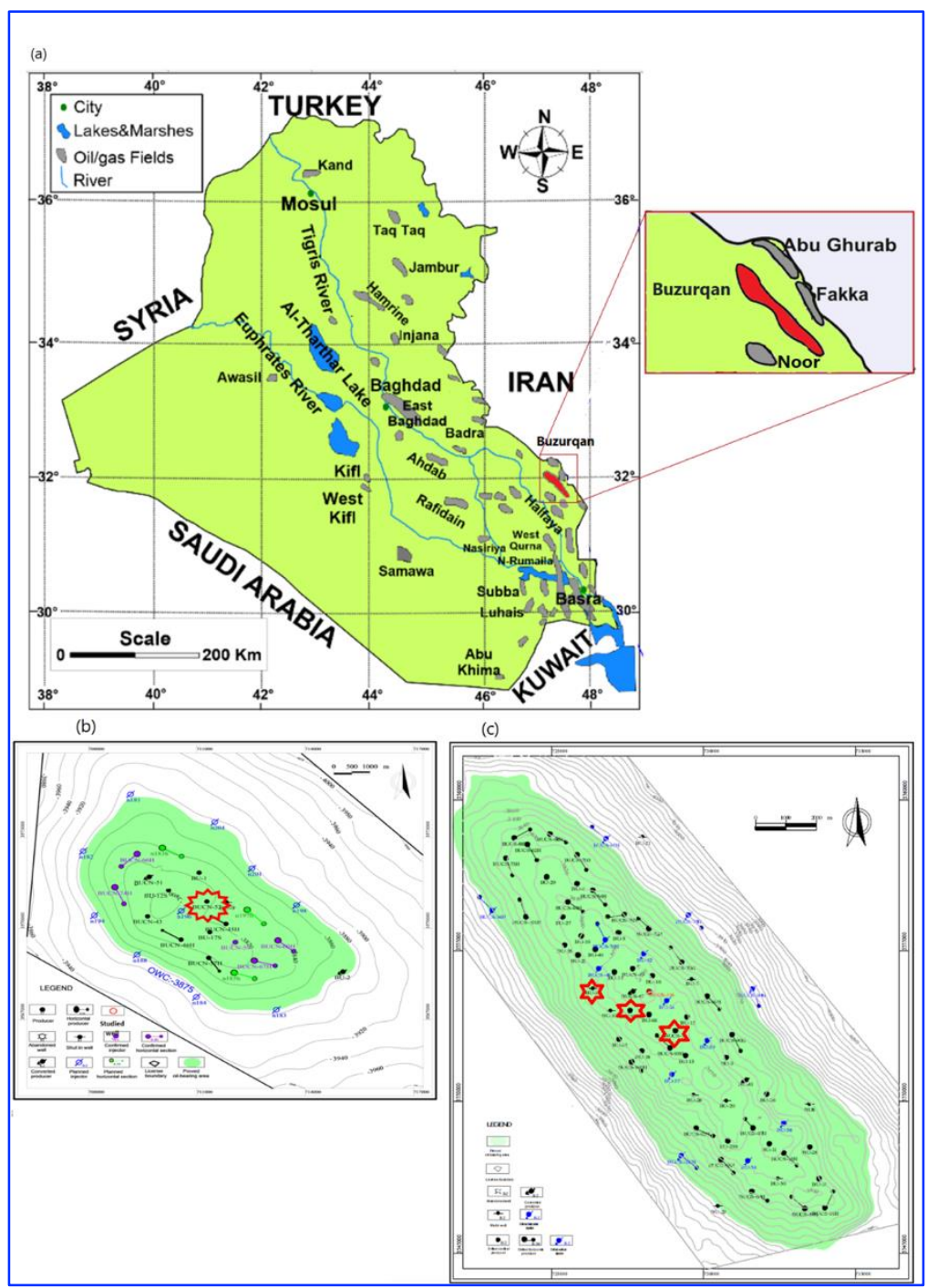

Fig. 1. (a) The Iraqi map shows most oil/gas fields. The red field is an area of interest, Buzurqan Field (from Mohammed, 2018); (b) north dome map of field, BUCN C the interest well in this study; (c) south dome map of field, BUCS A, BUCS B and BUCS D the interest wells in this study

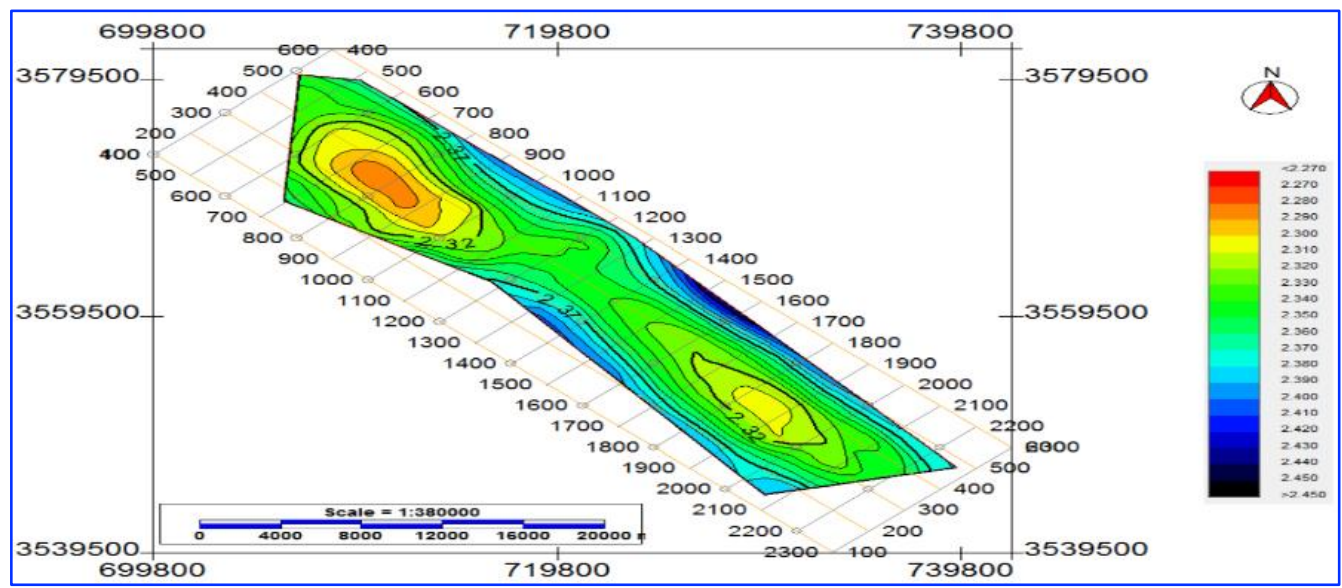

Fig. 2. The Structure map of the Buzurqan oil field (Aldarraji and Almayahi, 2019) 


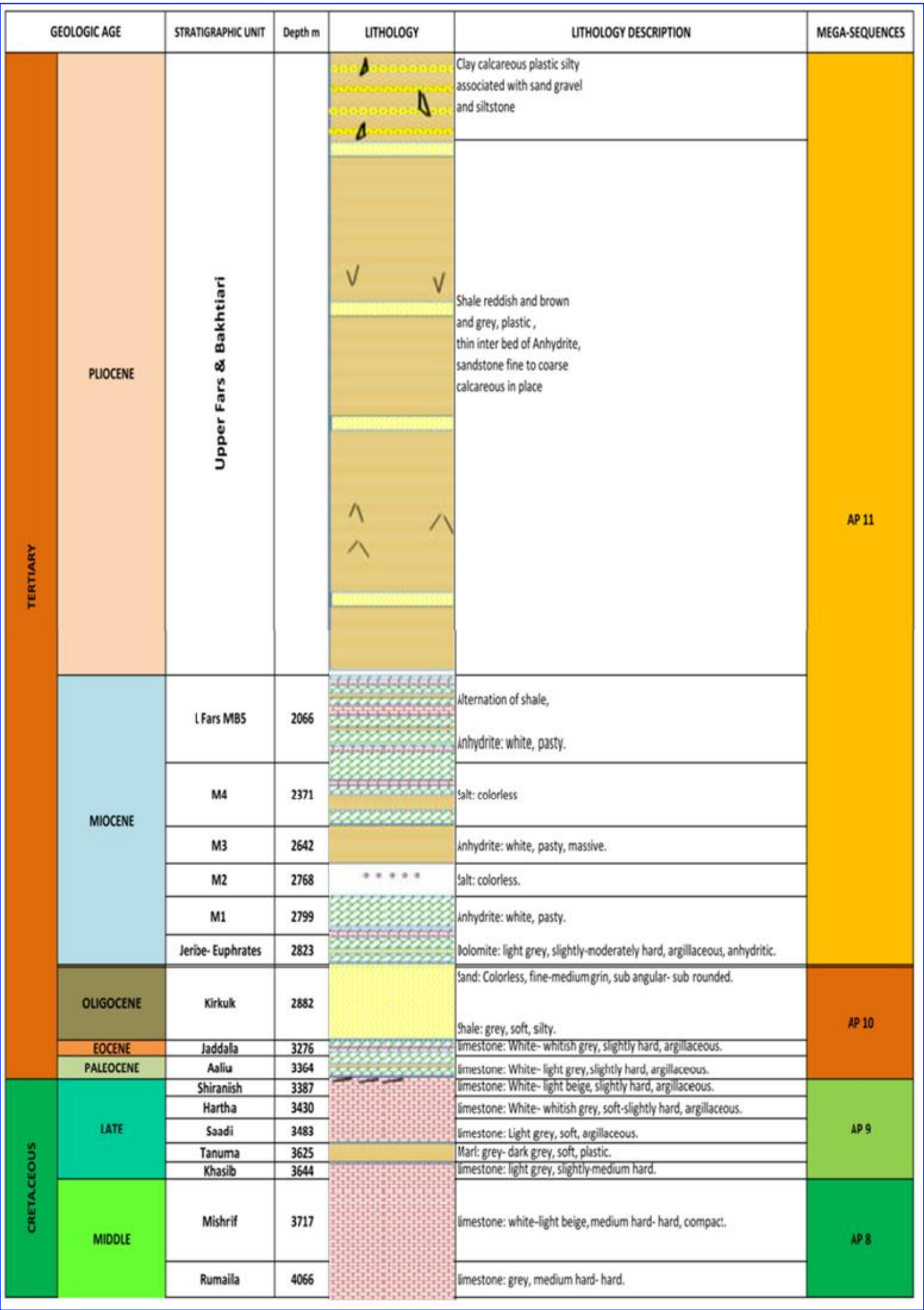

Fig. 3. Buzurgan Stratigraphy column (Aldarraji and Almayahi, 2019) 


\section{Materials and Methods}

To build a geomechanical model for each well in Buzurqan oil field, some of the data needed in a construction of the model was missing for some wells as shown in Table 1. The missing data were shear wave velocities and formation pore pressures. Therefore, data analysis has been made at first to determine which input parameter(s) has the most significant effect on shear wave velocity and pore pressure ANN models. Four wells have been used in this study. Datasets of BUCS A (located in the south dome of Buzurqan oil field) will be used to develop the new ANN-models, while data sets of BUCS B (located in the south dome) and datasets of BUCN C (located in the north dome of Buzurqan oil field) will be then used to validate the developed models. For constructing a 1D MEM, databases of BUCS D (located in south dome) will be used for determining the optimum mud weights.

Table 1. Available and non-available well-logs of the wells used in the study area

\begin{tabular}{|c|c|c|c|c|c|c|}
\hline wells & RHOZ & DTc & GR & $\mathbf{P p}$ & DTs & Well status \\
\hline BUCS A & $\checkmark$ & $\checkmark$ & $\checkmark$ & $\checkmark$ & $\checkmark$ & $\begin{array}{l}\text { Development well of Pp } \\
\text { and DTs ANN models }\end{array}$ \\
\hline BUCS B & $\checkmark$ & $\checkmark$ & $\checkmark$ & - & $\checkmark$ & $\begin{array}{c}\text { Validation of Ppand DTs- } \\
\text { ANN models }\end{array}$ \\
\hline BUCN C & $\checkmark$ & $\checkmark$ & $\checkmark$ & $\checkmark$ & $\checkmark$ & $\begin{array}{c}\text { Validation ofPp and DTs- } \\
\text { ANN models }\end{array}$ \\
\hline BUCS D & $\checkmark$ & $\checkmark$ & $\checkmark$ & - & - & $\begin{array}{l}\text { Construction } \\
\text { of 1D-MEM }\end{array}$ \\
\hline
\end{tabular}

MATLAB program (2020) was used to develop new shear wave velocity and pore pressure ANN Models. After filled up the missing data, Techlog (2015) was used to construct 1D MEM. The process to construction the 1D-MEM model was discussed by several authors (Ali, 2003; Plumb et al., 2000). The procedure is consisting of estimating the magnitudes and orientations of the subsurface stresses (overburden stress, maximum and minimum horizontal stresses), as well as determination of pore pressure and mechanical rock properties (dynamic and statics). Vertical (overburden) stress at any point in the formation is equivalent to the weight of the formation materials above and it was computed by integrating the bulk density log (Equation 1) (Aadnøy \& Looyeh, 2011).

$$
\mathrm{S}_{\mathrm{v}}=\int_{0}^{\mathrm{z}} \rho \mathrm{g}(\mathrm{z}) \mathrm{dz}
$$

Where $S_{v}$ is vertical stress, $\rho$ is the bulk density of overlaying rock integrated with respect to the depth of interest (z), and g represents the gravity acceleration in $\mathrm{m} / \mathrm{s} 2$. The magnitudes of the minimum and maximum horizontal stresses were determined using the poro-elastichorizontal strain models as shown in Equations 2 and 3. (Fjaer et al., 2008; M D Zoback et al., 2003)

$$
\begin{aligned}
& S_{h}=\frac{E}{1-v^{2}} \varepsilon_{1}+\frac{v E}{1-v^{2}} \varepsilon_{2}+\frac{v}{1-v}\left(S_{v}-P_{P}\right)+P_{P} \\
& S_{H}=\frac{E}{1-v^{2}} \varepsilon_{2}+\frac{v E}{1-v^{2}} \varepsilon_{1}+\frac{v}{1-v}\left(S_{v}-P_{P}\right)+P_{P}
\end{aligned}
$$

Where $S_{\mathrm{h}}$ is the minimum horizontal stress, $S_{H}$ is the maximum horizontal stress, $v$ is static Poisson's ratio, E is static young's modulus, $\mathrm{Pp}$ is pore pressure and $\varepsilon_{1}$ is tectonic strain in the minimum horizontal stress direction and $\varepsilon_{2}$ is tectonic strain in the maximum horizontal stress direction. The horizontal strain values were estimated using mini-frac test calibration which are entered into TECHLOG as constant values. The horizontal stress azimuth was determined based on the observation 
of borehole breakout and the drilled induced fractures from the formation image logging (FMI). The image log data were obtained for the last drilled section $\left(8^{1 / 2}\right)$ of well BUCN E.

The dynamic rock mechanical properties have been calculated by combining the acoustic logs including both compressional and shear acoustic (Elastic waves) with the formation bulk density log by using Equations 4 to 7 (Fjar et al., 2008). According to the assumptions that the formation is homogeneous, isotropic, and elastic (Ghanem et al., 2021). First, the dynamic Young's (E), and Poisson's ratio $(v)$ moduli were computed using equations (4 and 5), then the dynamic shear $(G)$ and bulk (K) moduli computed using equations (6 and 7). (Mark D Zoback, 2010)

$E_{d}=\rho V_{s}^{2} \frac{3 V_{P}^{2}-4 V_{s}^{2}}{\left(V_{P}^{2}-V_{s}^{2}\right)}$

$K_{d}=\frac{E}{3(1-2 v)}$

$$
G_{d}=\frac{E}{2(1+v)}
$$

Where $E_{d}$ is dynamic Young modulus (Mpsi), $v_{d}$ is Poisson's ratio modulus, $K_{d}$ is dynamic bulk modulus, $G_{d}$ is dynamic shear modulus, $\rho$ is bulk density $(\mathrm{g} / \mathrm{cc}), \mathrm{Vp}$ is compressional wave velocity $(\mathrm{Km} / \mathrm{s})$ and Vs is shear wave velocity $(\mathrm{Km} / \mathrm{s})$. Static Young's Modulus was computed by using the developed correlation (Eq. 8). This equation was developed by the rock mechanical testing data that made by CNOOC 2015, including the static Young's modulus data. The developed correlation has a high-performance capacity $\left(\mathrm{R}^{2}=0.86\right)$ in estimating the static Young's modulus based on travelling time of compressional wave $(\mu \mathrm{sec} / \mathrm{ft})$.

$$
\mathrm{E}_{\text {static }}=48-0.5 * \mathrm{D}+0.008(\mathrm{DTc}-67.25)^{2}
$$

Where $E_{\text {static }}$ is static Young's modulus (GPa) and DTc is compressional wave slowness ( $\mu \mathrm{sec} / \mathrm{ft}$ ).

Static Poisson's ratio has been then calculated through a correlation developed based on dynamic Poisson's ratio as introduced in Eq. 9. (Schlumberger, 2015)

$$
\mathrm{v}_{\mathrm{S}}=\mathrm{PR}_{\text {multiplier }} * \mathrm{~V}_{\mathrm{d}}
$$

Where $v_{S}$ static Poisson's ratio and $V_{d}$ is dynamic Poisson's ratio. The default value of the PR multiplier is 1 , which it then decreases until reach the best match between the lab test points and the dynamic profile of Poisson's ratio.Unconfined compressive strength (UCS) which is defined as the capacity of rock to failure resistance has been estimated by using the developed correlation (Eq. 10). Rock mechanical testing data that made by CNOOC 2015, included Unconfined compressive strength (UCS), were used for developing Equation (10) with $\mathrm{R}^{2}=0.82$ to estimate unconfined compressive strength (UCS) based on travelling time of compressional wave slowness $(\mu \mathrm{sec} / \mathrm{ft})$.

$$
\mathrm{UCS}=15830-179 * \mathrm{DTc}+4.5 *(\mathrm{DTc}-73.7)^{2}
$$

UCS is unconfined compression strength (MPa), and DTc is compressional wave slowness $(\mu \mathrm{sec} / \mathrm{ft}$ ). For the internal friction angle estimation, a correlation that obtained from the rock mechanical test data mentioned by Sirat et al., 2015 was used. Tensile strength (TS) is computed based on a simple correlation from UCS as presented in Equation 11. (Schlumberger, 2015)

$$
\mathrm{T}_{\mathrm{S}}=\mathrm{k} * \mathrm{UCS}
$$

$\mathrm{K}$ is facies and zone-based factor, default: 0.01 .

\section{Result and Discussion}

This section represents the development of ANN models to estimate shear wave velocity and pore pressure using datasets of one well. Datasets from other two wells were then used to check the performance of the developed models. The continuous profiles of shear wave and pore pressure were 
then used to generate the geomechanical well logs along the depths of two wells in Buzurqan oil field. Wellbore stability analysis has been then performed and optimum mud weights to drill new wells in Buzurgan oil field are selected.

\subsection{Development of ANN Models}

\subsubsection{Development of shear wave ANN model}

Datasets of the BUCS-A well were used to develop the Vs model using ANN techniques. According to data analysis, the key input parameters of ANN model were the formation depth, bulk density (ROZH) and compressional velocity $(\mathrm{Vp})$, while the output function was the shear wave velocity (Vs). When comparing the predicted shear wave (output) values that determined by ANN with the actual shear wave (target) values, the statistical parameters (mean squared error (MSE) and the squared correlation coefficient $\left(R^{2}\right)$ are 0.979 and 0.977 , and the MSE-values are 0.052 and 0.055 for both the training and validation datasets, respectively (Fig. 4).

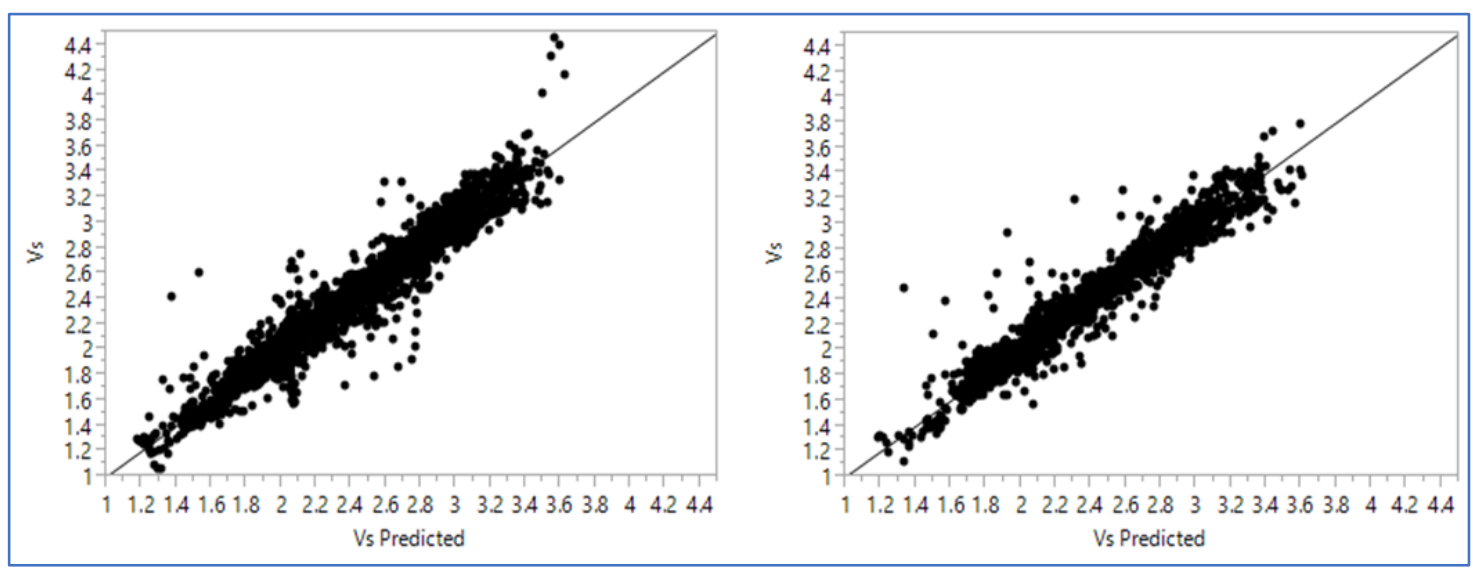

Fig. 4. Cross plot of predicted and actual $V_{S}$ datasets for (a) training and (b) validation

Equation 12 along with Table 2 showed the Vs model that has been developed using ANNs. Therefore, the Vs in carbonate reservoirs can be predicted using the weights and the biases of the neural networks, which are also combined with other conventional well logs including the formation depth, bulk density, and compressional wave.

$$
\mathrm{V}_{\mathrm{S}}=\sum_{\mathrm{i}=1}^{\mathrm{N}}\left[\mathrm{w}_{\mathrm{2}_{\mathrm{i}}} *\left(\frac{2}{1+\mathrm{e}^{-2\left(\mathrm{w}_{1_{\mathrm{i}, 1}} * \text { Depth }+\mathrm{w}_{\mathrm{1}_{\mathrm{i}, 2}} * \text { ROZH }+\mathrm{w}_{1_{\mathrm{i}, 3}} * \mathrm{~V}_{\mathrm{P}}+\mathrm{b}_{1_{\mathrm{i}}}\right)}}-1\right)\right]+\mathrm{b}_{2}
$$

Where $\mathrm{V}_{\mathrm{S}}$ is shear wave velocity $(\mathrm{Km} / \mathrm{sec}), \mathrm{ROZH}$ is bulk density $(\mathrm{g} / \mathrm{cc})$ and $V_{P}$ compressional velocity $(\mathrm{Km} / \mathrm{sec})$.

\subsubsection{Development of pore pressure ANN model}

Datasets of BUCS-A were also used to develop new model to estimate pore pressure using other measurable well logs. The true vertical depth (TVD), bulk density (RHOZ), gamma-ray (GR) and compressional travel time (DTc) are key parameters to determine pore pressure. Fig.5 showed the cross plots between the actual and predicted Pp for training and validation datasets. The obtained $R^{2}$ and RMSE are 0.98 and 41.2 for training datasets, while they are 0.98 and 33.9 for validation datasets, respectivel 
Table 2. The proposed empirical model's weights and biases

\begin{tabular}{lcccccc}
\hline Neuros & \multicolumn{1}{c}{$\boldsymbol{w}_{\boldsymbol{i}_{\mathbf{1}}}$} & \multicolumn{1}{c}{$\boldsymbol{w}_{\boldsymbol{i}_{\mathbf{2}}}$} & $\boldsymbol{b}_{\boldsymbol{1}_{\boldsymbol{i}}}$ & $\boldsymbol{b}_{\mathbf{2}}$ \\
\hline & Depth & $\mathrm{ROZH}$ & $\mathrm{Vp}$ & & & \\
1 & 0.008255 & 4.81962 & 2.251056 & -0.33938 & -29.8472 & 2.914529 \\
2 & -0.0069 & -3.77774 & -0.86031 & -0.39572 & 40.99208 & \\
3 & -0.00415 & 6.218303 & 0.74492 & 0.387379 & -3.48611 & \\
4 & 0.001348 & -0.78522 & -1.93252 & 0.683199 & 7.405387 & \\
5 & -0.00638 & -13.291 & -0.38016 & 0.153049 & 61.15253 & \\
6 & 0.009536 & 5.435835 & -1.10924 & 0.107186 & -44.5105 & \\
7 & -0.0005 & 0.678774 & 0.606784 & 2.130757 & -3.8725 & \\
8 & 0.005084 & 0.090774 & 0.78613 & 0.95457 & -22.2911 & \\
9 & 0.002731 & 3.503809 & -0.51794 & -0.82309 & -16.7904 & \\
10 & 0.01314 & -0.65895 & -1.9884 & 0.026425 & -37.3846 & \\
\hline
\end{tabular}
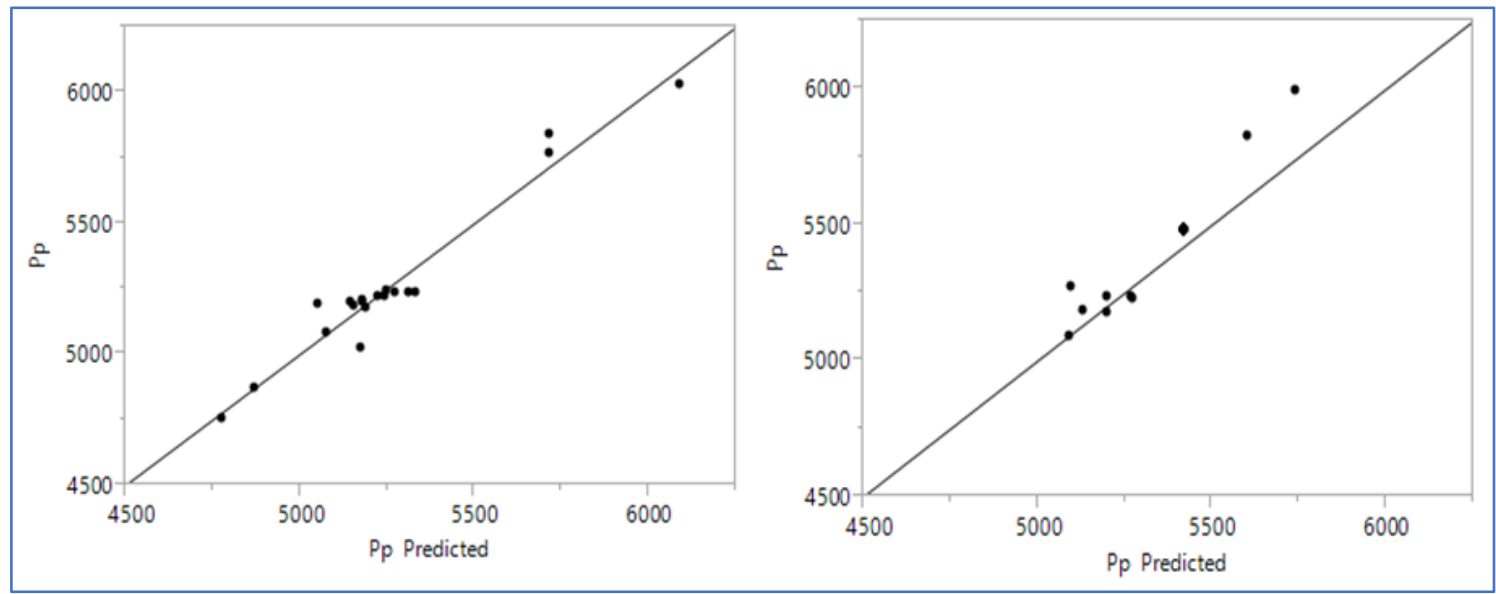

Fig. 5. Cross plot of predicted and actual $P_{P}$ datasets for(a) training, (b) validation

Equation 13 along with Table 3 showed the developed ANN-model that can be used to determine the Pp against carbonate formations using other conventional well logs. It is important to mention that the number of neurons to build the Pp-ANN model which has been selected by trial and error, and it is used 3 neurons for the model simplicity.

$$
P_{p}=\left[\sum_{i=1}^{N} w_{2} *\left(\frac{2}{\left.1+e^{-2\left(W_{1,1} * T V D+W_{1, i,}\right.}{ }^{* D T c}+W_{1,3} * G R+W_{1,4} * R H O Z+b 1\right)}\right)-1\right]+b 2
$$

Where Pp is Pore pressure (Psi), TVD is true vertical depth (m), DTc is compressional wave slowness (sec/ft), GR is gamma ray (API), ROZH is bulk density (g/cc). 
Table 3. The proposed empirical model's weights and biases

\begin{tabular}{|c|c|c|c|c|c|c|c|}
\hline Neurons & & $w_{i_{1}}$ & & & $w_{i_{2}}$ & $b_{1_{i}}$ & $b_{2}$ \\
\hline & TVD & DTC & GR & RHOZ & & & \\
\hline 1 & -0.00392 & -0.00966 & 0.004936 & -0.09084 & $\begin{array}{l}-563.794 \\
\end{array}$ & 12.47926 & 5278.361 \\
\hline 2 & -0.03479 & -0.49375 & -1.07499 & 21.6538 & -239.456 & 169.3317 & \\
\hline 3 & -0.08035 & -0.00836 & -0.07134 & -1.2378 & -389.101 & 319.6133 & \\
\hline
\end{tabular}

\subsection{Validation of ANN Model}

To figure out whether an improvement is achieved in this study, datasets of other two wells, BUCS $\mathrm{B}$ in south dome and BUCN C in the north dome of the Buzurqan oil field, were used to check the performance capacity of the developed models in determining the shear wave velocities and pore pressures against carbonate formations.

\subsubsection{Validation of shear wave ANN model}

Data sets of two wells, BUCS B in south field and BUCN C in the north field have been used in this study to check the performance capacity of Vs-ANN model in estimating shear wave velocities. The results showed that the ANN model was successfully checked for prediction of Vs using conventional well $\log$ data as shown in Fig. 6 (Figs. $6 \mathrm{a}$ and $6 \mathrm{~b}$ for BUCN C and BUCS B wells, respectively).
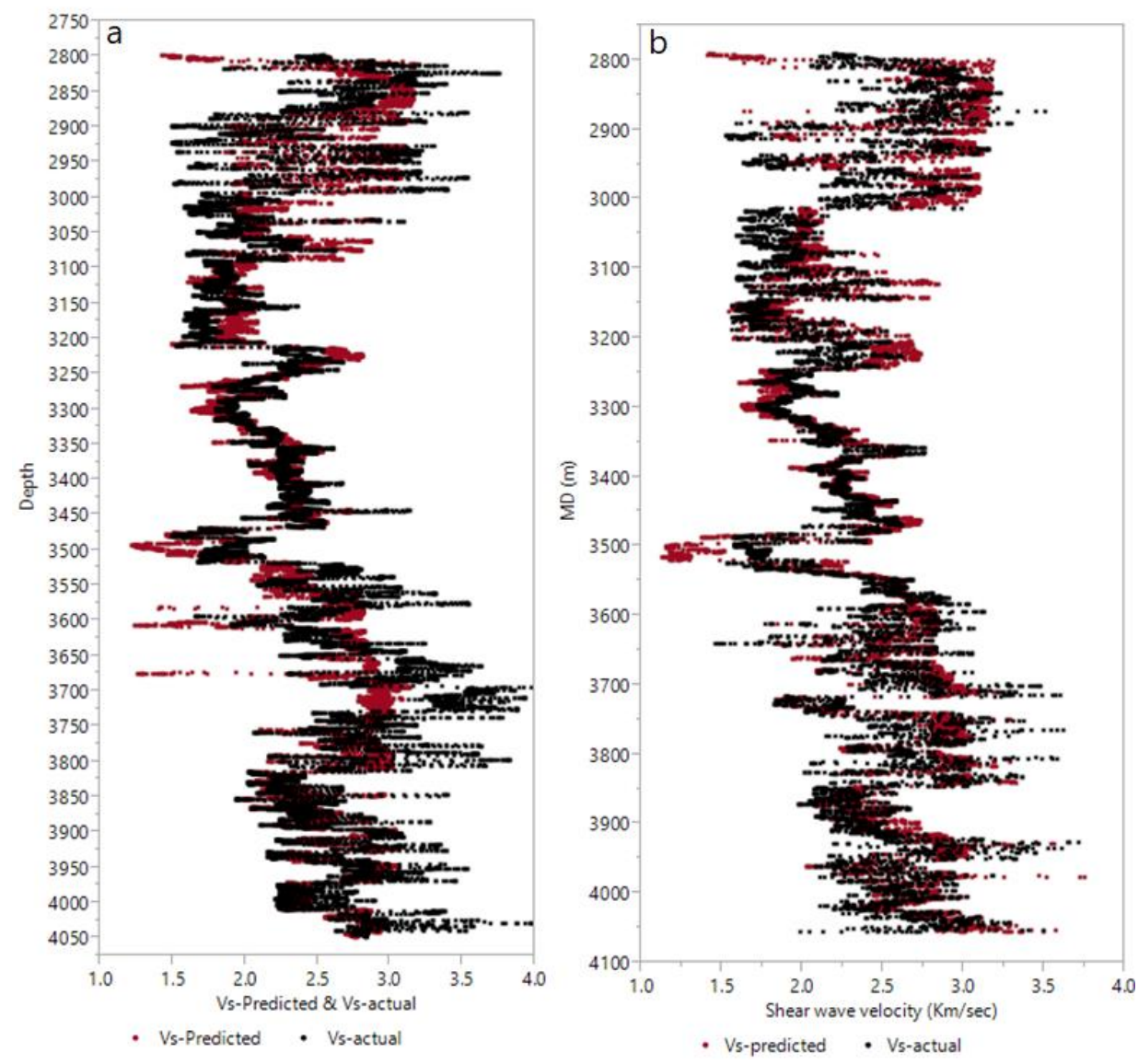

Fig. 6. Validation of the Vs-ANN model (a) the validation in BUCN C well, (b) the validation in BUCS B well 


\subsubsection{Validation of Pore pressure ANN model}

The databases of the BUCS B and BUCN C wells were used to test the performance capacity of the new ANN model in predicting pore pressure. The results in Fig.7 showed that the developed ANN model was very powerful in predicting Pp using the weights and the biases of the network.

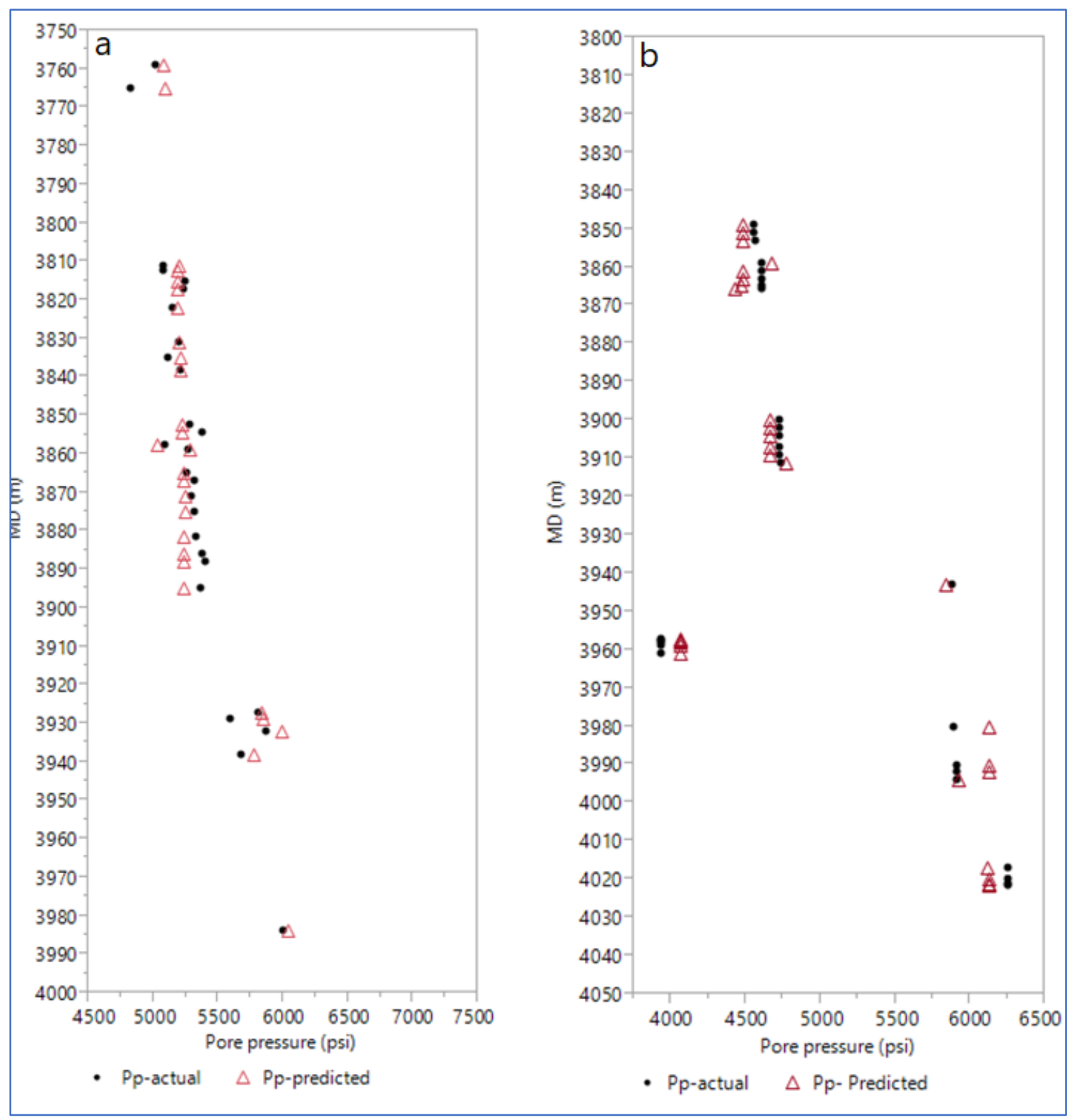

Fig. 7. Validation of the Pp-ANN model (a) the validation in BUCN C well, and(b) the validation in BUCS B well

\subsection{Construction of 1D MEM}

After estimating the missing data of shear wave velocity and pore pressure by using the developed ANN models, databases of BUCS D well in the Buzurqan oil field were used to generate a 1D mechanical earth modeling. Wire line logs including compressional slowness, shear slowness, bulk density, gamma ray etc. were used to compute the log derived rock elastic and strength properties as well as in-situ stresses magnitudes and orientations. Fig. 8 displays the output window of TECHILOG 1-D representation of a MEM consists of tracks. From left to right, track two in Fig. 8 showed the 
dynamic elastic properties, which are calculated using Equations 4 to 7. It is very important to mention that shear wave velocity is a key parameter for determining most of these elastic properties. The third track of Fig. 8 presents the results of the static Young's modulus (YME_STA) which have been estimated using the developed correlation (Eq. 8). The estimated static Young's modulus profile exhibited good agreement with the direct measured Young's modulus points (Lab_YME).

The static Poisson's ratio (PR_STA) was also correlated based on Equation 9. The constant value (PR multiplier) has been estimated as (0.9) by matching the dynamic values with the lab results (Lab_PR) where a good consistency profile was observed as shown in the fourth track of Fig. 8. Unconfined compressive strength (UCS) has been determined by correlation (Eq. 10), which it developed using rock mechanical testing data. The estimated unconfined compressive strength (UCS) profile exhibited a good agreement with the direct measured unconfined compressive strength (UCS) points (Lab_UCS) as shown in the fifth track of Fig. 8. Internal fraction angle is then estimated for analyzed well by using Sirat et al. (2015) correlation. Tensile strength (TS) is computed based on a simple correlation, Eq.11. from UCS proposed by Schlumberger Techlog software designers as shown in the fifth track for Fig. 8. Track 6 shows pore pressure (Pp), maximum horizontal stress (SH), vertical stress $(\sigma v)$, and minimum horizontal stress $(\mathrm{Sh})$ which are calculated according to poroelasic horizontal strain model which implicate both elastic modulus and Poisson's ratio using Equations 1 to 3. Pore pressure $(\mathrm{Pp})$ calculated using the new developed Pp-ANN model. The stress regime in majority of the formations was found to be the normal fault regime $\left(S_{V}>S_{H}>S_{h}\right)$.

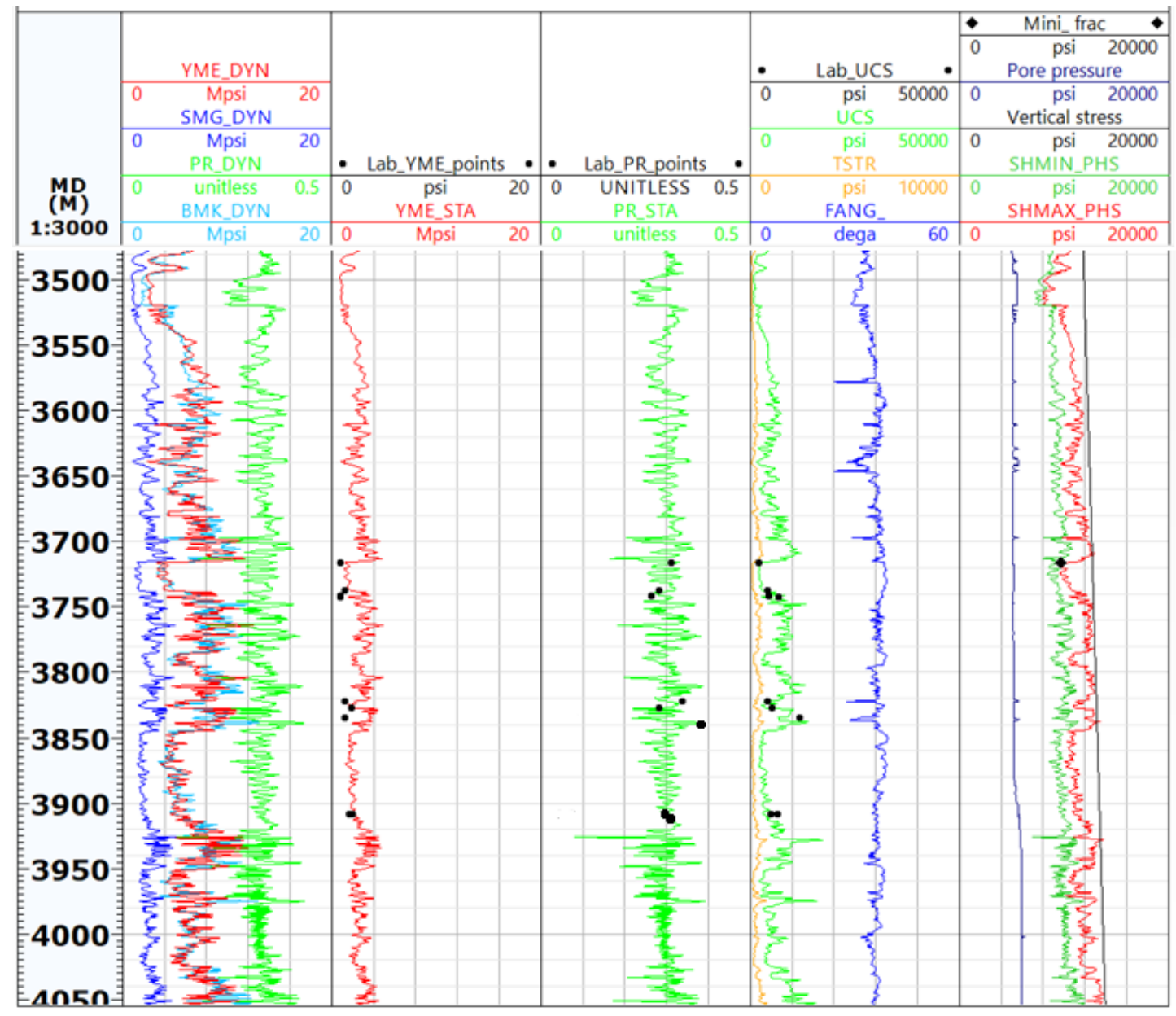

Fig. 8. Geomechanical model components of BUCS D by using the Vs and Pp ANN models

The orientation of the minimum horizontal stress was determined based on the observation of borehole breakout and drilled induced fractures from Formation imaging logging (FMI) as shown in 
Fig. 9. The results of this figure showed that the orientation of minimum horizontal stress is ranged between 100 and 110 degrees, across the field and thus the orientation of maximum horizontal stress is ranged between 12 to 20 degrees from the North.

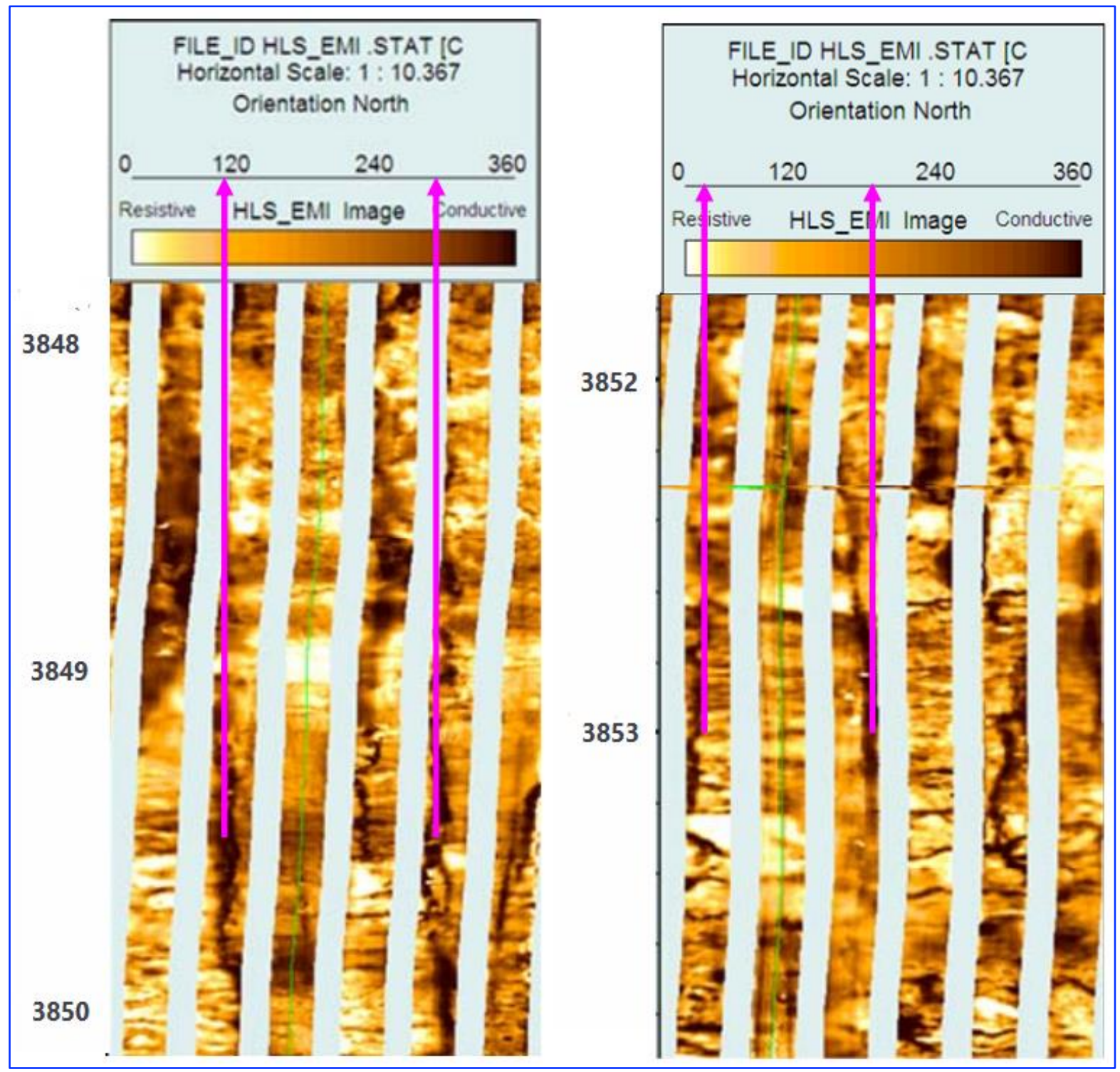

Fig.9. Formation imaging logging of BUCN-E (the left is collapse azimuth angle; the right is fracture azimuth angle

\subsection{Wellbore Stability Analysis}

Wellbore stability analysis has been made on the datasets of well BUCS D to validate the generated geomechanical well logs using ANN techniques model through comparing the predicted borehole instability with the actual wellbore failures displaced by the caliper log. Though using the Mogi-failure criterion, the results showed a high matching between the actual and predicted wellbore failures, which can be recognized by the enlargement in the wellbore size or caliper log as shown in Fig. 10.

The third track of Fig. 10 illustrates the wellbore size and borehole caliper logs, which represents the actual wellbore condition. The forth track in Fig. 10 represents the mud weight window that consists of pore pressure, shear failure pressure, breakdown pressure, and minimum horizontal stress. On the left side, the grey colored profile defined the mud weight indicative to the kick and the yellow-colored 
profile shows the limit of mud weight corresponding for shear failure, when the actual mud weight being lower than one or both of them the shear failure and/or kick will encounter. On the right side, the dark blue profile appears the mud weight limit for mud losses or initiate of mud diffusion to the formation while the light blue profile reveals the mud weight limit that represents the minimum horizontal stress. Breakdown failure and Mud loss will be predicted if the actual mud weight exceeds both or one of them. The fifth track of Fig. 10 shows the predicted rock failure according to the applied failure criterion.

The predicted failure varied between red-colored wide breakouts $\left(\sigma_{\theta}>\sigma_{z}>\sigma_{r}\right)$, the green-colored shallow Knockouts $\left(\sigma_{z}>\sigma_{\theta}>\sigma_{r}\right)$ and blue-colored high angle tensile $\left(\sigma_{r}>\sigma_{\theta}>\sigma_{z}\right)$. From Fig. 10, the minimum mud weights that required to drill the production section without significant borehole breakout are within 1.3 to $1.35 \mathrm{~g} / \mathrm{cc}$. As a comparison with the offset well data, the used mud weight was less than $1.3 \mathrm{gm} / \mathrm{cc}$. Therefore, the range of the proposed mud weights are optimum mud weights which can be used to drill new wells in Buzurgan oil field without expected wellbore stability problems. Furthermore, the results of wellbore stability analysis revealed that the rock tensile fracturing or the wellbore breakdown failure is expected when the used mud weight exceeds $1.5 \mathrm{~g} / \mathrm{cc}$.

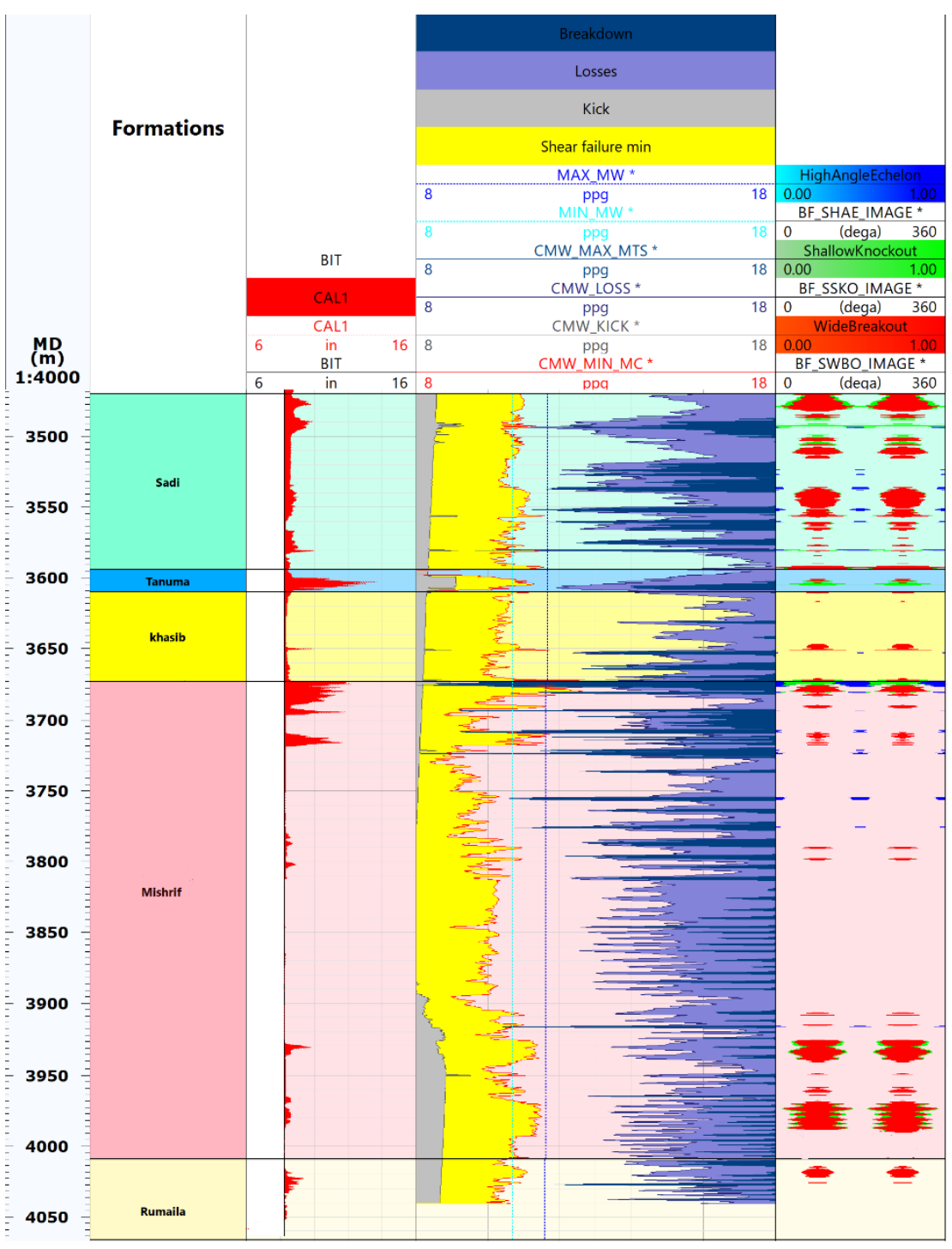

Fig. 10. Wellbore failure predicted by using the synthesized geomechanical well logs of BUCN 


\section{Conclusions}

Accurate estimation of shear wave and pore pressure in carbonate reservoirs is an important task for many applications related to reservoir geomechanics. This study presents ANN models that have been developed to guarantee the accuracy of predicting Vs and Pp using conventional well logs. According to our knowledge, this study can be considered as the first study in the Buzurqan oil field which can be used for future applications related to reservoir geomechanical.

- The ANN technique is reasonably well matched to the measured well logs in estimating Vs and Pp within carbonate formations.

- The results of this study showed that conventional well logs including formation depth, compressional wave, bulk density, and gamma ray are key parameters for estimating the shear wave and formation pore pressure in carbonate reservoirs.

- The correlation coefficients for ANN models were found to be very high for shear wave and pore pressure models, and the root mean square errors were also found to be very low for these models. This shows the capability of Vs and Pp estimate using the weights and the biases of ANN with high performance capacity.

- The presented models are closely resembled the measured Vs and Pp data when datasets of other two wells are used to validate the accuracy of these predictive models.

- The orientation of minimum horizontal stress is ranged between 100 and 110 degrees, across the Buzurgan oil field and thus the orientation of maximum horizontal stress is ranged between 12 to 20 degrees from the North.

The results of 1-D MEM revealed a high matching between the predicted mud weights using the synthesized geomechanical well logs and the actual borehole failures. The wellbore stability analysis for BUCS D well revealed that majority of the borehole enlargement and wellbore instability related to drilling problems can be attributed to the inadequate mud weight selection while drilling operations. The required mud weights to drill the production section of Buzurgan oil field without expected wellbore stability problems are within 1.3 to $1.35 \mathrm{~g} / \mathrm{cc}$. In contrast, the breakdown failure is expected when the mud weight reaches $1.5 \mathrm{~g} / \mathrm{cc}$. The presented ANN-models within this work can be extended to different applications related to reservoir geomechanics within the Buzurgan oil field including sand production, fault reactivation, as well as reservoir compaction and subsidence.

\section{Acknowledgements}

The authors are grateful to the Editor in Chief Prof. Dr. Salih M. Awadh, the Secretary of Journal Mr. Samir R. Hijab and the Technical Editors for their great efforts and valuable comments.

\section{References}

Aadnøy, S., \& Looyeh, R. 2011. Stresses around a wellbore. Petroleum Rock Mechanics Drilling Operations and Well Design, First Edition, 10, 157.

Abdul Aziz, Q.A., Hussein, H.A., 2021. Mechanical rock properties estimation for carbonate reservoir using laboratory measurement: A case study from Jeribe, Khasib and Mishrif Formations in Fauqi oil field. Iraqi Geological Journal, 54(1E) 88-102.

Abdul Majeed, R. K., Alhaleem, A. A., 2020. Estimation of shear wave velocity from wireline logs data for Amara oil field, Mishrif Formation, southern Iraq, Iraqi Geological Journal, 53(1A), 36-47.

Ahmed, A., Elkatatny, S., Ali, A., Mahmoud, M., \& Abdulraheem, A. 2019. New model for pore pressure prediction while drilling using artificial neural networks. Arabian Journal for Science and Engineering, 44(6), 6079-6088.

Al-Malikee, H. S., Al-Najim, F. M. 2018. Indirect prediction of rock elasticity and compressibility strength using well $\log$ data at selected sites within Rumaila Oilfield, Southern Iraq. Iraqi Geological Journal, 41-53.

Ali, A. H., 2003. Watching rocks change-mechanical earth modeling. Oilfield Review, 15, 22-39. 
Akhundi, H., Ghafoori, M., Lashkaripour, G., 2014. Prediction of shear wave velocity using artificial neural network technique, multiple regression and petrophysical data: A case study in Asmari Reservoir, Journal of Geology, 4(2), 303-313.

Aldarraji, M.Q., Almayahi, A.Z., 2019. Seismic structure study of Buzurgan Oil field, Southern Iraq, Iraqi Journal of Science, 60(3), 610-623.

Al-Ismaily, O. S., 2017. Use borehole image log technique to estimate Mishrif Reservoir characterization in Buzurgan oilfield. Ph.D. Thesis, Basrah University.

Bingham, G. 1965. A new approach to interpreting rock drill ability. Technical manual reprint, Oil and Gas Journal, 1965. $93 \mathrm{P}$.

CNOOC, 2015. Missan technical support team and CNOOC Research institute. Geological Analysis of Buzurgan Oil field, Missan Oil Company, 3.

Eaton, B. A. 1975. The equation for geopressured prediction from well logs. Fall Meeting of the Society of Petroleum Engineers of AIME.

Elkatatny, S.M., Zeeshan, T., Mahmoud, M.A., Abdulraheem, A., Mohamed, I., 2018. An integrated approach for estimating static Young's modulus using artificial intelligence tools. Neural Computing and Applications, 31(738), 4123-4135.

Eskandari, H., Rezaee, M.R., Mohammadnia, M., 2004. Application of multiple regression and artificial neural network techniques to predict shear wave velocity from wireline $\log$ data for a carbonate reservoir SouthWest Iran, Canadian Journal of Exploration Geophysics, 29(7), 42-48.

Fjaer, E., Holt, R. M., Horsrud, P., Raaen, A. M., \& Risnes, R. 2008. Mechanics of hydraulic fracturing. Developments in Petroleum Science, 53, 369-390.

Fjar, E., Holt, R. M., Raaen, A. M., \& Horsrud, P. 2008. Petroleum related rock mechanics. Elsevier.

Ghanem, F. K., Al Amoush, H., \& Al-Tarazi, E. 2021. Geotechnical engineering evaluation of superficial deposits utilizing seismic methods at Al al-Bayt University, Jordan. Iraqi Geological Journal, 11-28.

Hadi, F., Eckert, A., \& Almahdawi, F. 2019. Real-time pore pressure prediction in depleted reservoirs using regression analysis and artificial neural networks. SPE Middle East Oil and Gas Show and Conference, MEOS, Proceedings, 2019.

Hadi, F. A., and Nygaard, R., 2018. Shear wave prediction in carbonate reservoirs can Artificial neural Network outperform regression Analysis? In 52nd US Rock Mechanics, Geomechanics Symposium. American Rock Mechanics Association.

Jorden, J. R., \& Shirley, O. J. 1966. Application of drilling performance data to overpressure detection. Journal of Petroleum Technology, 18(11), 1387-1394.

Mohammed, A. K. A. 2018. Reservoir characteristics of Khasib formation in Amara field, southern Iraq. Iraqi Geological Journal, 54-74.

Plumb, R., Edwards, S., Pidcock, G., Lee, D., \& Stacey, B. 2000. The mechanical earth model concept and its application to high-risk well construction projects. IADC/SPE Drilling Conference.

Rehm, B., \& McClendon, R. 1971. Measurement of formation pressure from drilling data. Fall Meeting of the Society of Petroleum Engineers of AIME.

Schlumberger., 2015. Techlog pore pressure prediction and wellbore stability analysis workflow, solutions training.

Sirat, M., Ahmed, M., \& Zhang, X. 2015. Predicting hydraulic fracturing in a carbonate gas reservoir in Abu Dhabi using 1D mechanical earth model: uncertainty and constraints. SPE Middle East Unconventional Resources Conference and Exhibition.

Zamora, M., \& Lord, D. L. 1974. Practical analysis of drilling mud flow in pipes and annuli. Fall Meeting of the Society of Petroleum Engineers of AIME.

Zhang, J., 2011. Pore pressure prediction from well logs: methods, modifications, and new approaches, EarthScience Reviews, 108(1), 50-63.

Zoback, M D, Barton, C. A., Brudy, M., Castillo, D. A., Finkbeiner, T., Grollimund, B. R., Moos, D. B., Peska, P., Ward, C. D., \& Wiprut, D. J. 2003. Determination of stress orientation and magnitude in deep wells. International Journal of Rock Mechanics and Mining Sciences, 40(7-8), 1049-1076.

Zoback, M. D., 2010. Reservoir geomechanics. Cambridge university press. 